\title{
Are Mediterranean forest ecosystems under the threat of invasive species Solanum elaeagnifolium?
}

\author{
Georgios Formozis, \\ Marianthi Tsakaldimi, \\ Petros Ganatsas
}

\begin{abstract}
Solanum elaeagnifolium Cav. is one of the most invasive plant species worldwide that colonizes crops and human disturbed lands, while it appears at the edge of forest ecosystems. Its control still remains an unsolved problem around the world. Understanding its distribution under predicted climate change, could contribute to an effective management and conservation of ecosystems in the future. This research was conducted in order to investigate the capacity of this species to invade Mediterranean forest ecosystems, and if the allelopathy effects of forest tree species could control its regeneration, thus contributing to a natural and biological management practice aimed to prevent the species from pervading into Mediterranean forest ecosystems. Results showed that $S$. elaeagnifolium can establish itself outside and along the forest edges, but not in a typical forest environment. The leaf extracts of $\mathrm{Pi}$ nus brutia, Cupressus sempervirens, Quercus coccifera and Quercus pubescens significantly inhibited the germination of S. elaeagnifolium. Root regenerative ability of the cuttings was also significantly affected by the leaf extract treatments. $P$. brutia leaf extract had significantly the highest inhibitory activity on root regenerative ability of the species. Despite the promising findings of this study, absence of S. elaeagnifolium in Mediterranean forest ecosystems can be attributed to a combination of factors. In the context of climate change, especially in hot and dry Mediterranean areas, and the expected increase of forest disturbances (e.g., fires), the findings of the study could contribute towards the restriction of this invasive alien species by an appropriate management of forest ecosystems.
\end{abstract}

Keywords: Alien Species, Allelopathy, Forest Conservation, Plant Invasion, Weed Control matter soils (Uludag et al. 2016, Gitsopoulos et al. 2017). Taproots can penetrate the soil to depths of $2 \mathrm{~m}$ or more, a characteristic that enables plants to tolerate drought and outperform shallow-rooted vegetation, especially during summer dry periods. Moreover, Solanum elaeagnifolium tolerates shade and becomes quite abundant below trees and near farm buildings (Boyd \& Murrary 1982a, Mekki 2007).

Solanum elaeagnifolium is considered among the worst weeds, as an agricultural, ruderal and environmental weed (Brunel 2011, Sayari et al. 2016), and an aggressive, invasive alien plant species in many countries worldwide (Mekki 2006). Particularly - Stanton et al. 2007), an conditions, and it thrives on poor organic

\section{Introduction}

known as Silver-leaf nightshade, is a perenthrough dormant buds on its root Solanum elaeagnifolium grows in a wide range of environmental conditions (Mekki 2007), tolerating relatively high temperatures $\left(20-34{ }^{\circ} \mathrm{C}\right)$, low annual rainfall $(250$ in Greece and Morocco, this species has gone from a few accidental introductions over 60 years ago to near monospecific populations in recent years (Uludag et al. 2016). It has spread almost all over Greece, following the road network, creating problems mainly in orchards, but it also appears at the edges of natural ecosystems. Krigas et al. (2016) reported that the minimum winter and maximum summer temperatures shape its distribution, soil disturbance related to agricultural activities favour its invasion, while road traffic facilitates its spread. They reported that its populations presented a $1750 \%$ increase in the last decades and they invade $10 \%$ of the sites of the Greek Natura 2000 network. In conclusion, S. elaeagnifolium invasion is intensively ongoing.

It mainly colonizes disturbed areas, mostly man-made habitats such as roadsides, construction sites, livestock feeding, cultivated fields, riverbanks, canal sides, wastelands and open spaces (Mekki 2006, EPPO 2007, Sayari et al. 2016). Due to its high competitiveness, it threatens natural ecosystems, displaces native plants and reduces crops' production by absorbing soil nutrients and humidity (Brunel et al. 2010, Sayari et al. 2016). 
Although S. elaeagnifolium grows in a wide variety of habitats, however, there is no study on its distribution in forest ecosystems. Thus, it remains unknown whether its competitiveness could create problems in forest ecosystems, and to what ex tent it could displace indigenous forest species and alter ecosystem functions. In the latter case, what could be an effective way to mitigate its effects? Invasive alien species are well-known by the scientific community as one of the major threats to biodiversity. In forest ecosystems, invasive alien species can cause hybridization, trans mission of diseases and species competition (Langmaier \& Lapin 2020). The understanding of the distribution dynamics of in vasive alien plant species under predicted climate change could contribute to an ef fective management and conservation of ecosystems in the future (Thapa et al. 2018), as the response of invasive plants to climate change may increase their ability to establish and alter Mediterranean ecosys tem processes and function (Phillips et al. 2019, Langmaier \& Lapin 2020). As invasive plants native to tropical countries can thrive under higher temperatures they could consequently displace native species under the warming climate change conditions (Adhikari et al. 2019).

S. elaeagnifolium is a weed very difficult to control in agricultural areas, even with herbicides, or by mechanical and biologica means (EPPO 2007), most likely because it shows a deep and extensive root system (Baye et al. 2007, Stanton et al. 2011). This characteristic enables it to endure considerable drought and survive shallow-rooted vegetation (Mekki 2006, 2007).

Recent studies reported that the existing vegetation (natural ecosystems or crops) can suppress weeds due to competitive and allelopathic effects. The term allelopathy refers to biochemical interactions be tween all types of plants, including microorganisms (Rice 2012). Cummings et al. (2012) reported that allelopathy may be an additional useful tool to help reduce the persistence of exotic weeds and facilitate the restoration of forests. Sturm et al. (2018) reported an important role of the crops' allelopathic effects on weed suppression and concluded that the rapid crop germination and development, combined with a dense crop canopy and high soil coverage, is a prerequisite for effective weed suppression. Given the keen interest in eco-friendly practices for weed control, the use of allelopathy could be combined with other weed control methods within an in tegrated weed management strategy. For example, the allelopathic mechanisms can be incorporated in agro-ecosystems for weed control through several ways such as the inclusion of allelopathic crops in crop rotations, the use of their residues for cover cropping, or by selection of the most active allelochemicals to be used as bioherbicides (Scavo \& Mauromicale 2020). In the case of $\mathrm{S}$. elaeagnifolium, it may also be combined with current chemical control methods (Cambardella \& Elliott 1992, Choudhary \& Bordovsky 2006, Gitsopoulos et al. 2017).

The spread of S. elaeagnifolium in forest ecosystems has not been considered until recently (Langmaier \& Lapin 2020). As far as we know, this is the first study conducted to address why $S$. elaeagnifolium does not colonize forest ecosystems, which have been proved in some cases to be resistant to the colonization of other invasive plants (Hashim et al. 1975, Lill \& Waid 1975, Singh \& Kohli 1992, Tolliver et al. 1995, Morgan \& Overholt 2005, Fernandez et al. 2006, Cummings et al. 2012). Also, Zhang et al. (2012) reported that leaf essential oils from four species of Eucalyptus inhibited the germination, and the root and shoot growth of S. elaeagnifolium.

Our hypothesis was that the extracts produced by the decomposition of fallen leaves and released to the ground with rain may reduce $S$. elaeagnifolium germination and rooting ability, and thus hinder species recruitment in forests. Therefore, this study aimed to: (i) estimate the species invasion into Mediterranean forest ecosystems, as well as the intensity and spread distance of the invasion; (ii) determine the morphological characteristics of the fruits of S. elaeagnifolium harvested from specific ecosystems, where the species dominates; and (iii) examine whether leaf extracts of forest tree species can control its regeneration, and prevent species from spreading into Mediterranean forest ecosystems.

\section{Materials and methods}

\section{Description of experimental procedure}

In order to achieve the aim of the study, a field campaign was organized to collect all the necessary field data and materials. These included data on S. elaeagnifolium distribution, collection of seeds and root cuttings of the species, as well as sampling of leafs and needles of the forest species. Then, after the preparation of all materials in the laboratory, two different experiments were carried out in order determine the effect of leaf extracts of forest species on seed germination and root regenerative ability of S. elaeagnifolium.

\section{Field data collection for $\mathrm{S}$.}

\section{elaeagnifolium distribution}

We designed a field campaign to collect data of S. elaeagnifolium distribution in the dominant forest ecosystems at the eastern part of Thessaloniki, northern Greece, where the species was initially recorded in 1940. We selected two forest ecosystems that dominate the area, namely Quercus coccifera L., and Pinus brutia Ten. ecosystems (40.577342 N, $23.059834 \mathrm{E})$. Ecosystem of Q. coccifera comprises a low-height degraded natural woodland used for grazing in the past, with mean canopy density of $60-70 \%$ and a mean plant height of 2.5 $3.0 \mathrm{~m}$. Forest of P. brutia is a 60-year-old plantation with canopy cover of $60-70 \%$, and mean tree height of $12 \mathrm{~m}$. In order to quantify the intensity and the distance $S$. elaeagnifolium invades inside the forest ecosystems, we selected two forest edges (one in each ecosystem type) at least 300 $\mathrm{m}$ long each. For selecting the sampling method, we took into consideration that any species invasion to a forest ecosystem likely occurs within the edge zone (Pauchard \& Alaback 2006) and to some distance (e.g., 50-100 m) from the edge towards the interior of the forest environment (Honnay et al. 2002).

The sampling was conducted in five different transects separated at least $50 \mathrm{~m}$ each other, oriented to the south-southeast and established orthogonally to the edges in each of the two dominant type of forest ecosystems. In each transect, beginning from the forest edge, a plot of $3.5 \times$ $3.5 \mathrm{~m}$ was established, and other four similar plots were established inside the forest at 10, 20, 30 and $50 \mathrm{~m}$ from the forest edge (Honnay et al. 2002). In each plot, the number of S. elaeagnifolium individuals was recorded.

\section{Seed collection}

Ripe fruits of S. elaeagnifolium were collected from two populations in northern Greece; one from the eastern part of Thessaloniki $(40.550441 \mathrm{~N}, 23.012215 \mathrm{E})$, which is considered to be the oldest population in Greece, and the other one from the Dion agricultural area $(40.163285 \mathrm{~N}, 22.484890$ E), which is located approximately $100 \mathrm{~km}$ south from the Thessaloniki population. Twenty berries per plant were harvested from 30 randomly sampled individuals per population in early November 2016 and transported to the laboratory.

For the determination of the fruits morphological quantitative characteristics, 50 berries from each population were randomly selected and measured. Measurements were: horizontal diameter and vertical length of fruits, the diameter of the imprint left the stem attachment and the number of seeds per berry. Measurements were made using a Vernier caliper.

Subsequently, seeds were extracted from the fruits with a cutter. The pericarp was cut, and the seeds were washed for one hour under running water to remove most of the sticky film from the seed coat (Boyd \& Murray 1982a, Stanton et al. 2012). Seeds were submerged in water for half an hour and those floated were considered hollow and removed. The seeds were then air dried at room temperature $\left(25^{\circ} \mathrm{C}\right)$ for 24 hours on three layers of filter paper, and were stored in airtight containers in the refrigerator at $5{ }^{\circ} \mathrm{C}$ until the beginning of the experiment (approximately for 3 months Boyd \& Murray 1982a).

\section{Cuttings preparation}

On March 10, 2017 mature woody plants along with their main vertical root were randomly collected by hand from the field 
in the area of Thessaloniki. Once in the laboratory, the main vertical root was cut into pieces of $1 \mathrm{~cm}$ with a pruner and a ruler (Stanton et al. 2011). The cuttings were then washed from soil with distilled water and were sprayed with fungicide. The cuttings stayed under moist conditions in a plastic bowl until their planting.

\section{Preparation of the trees' leaf extracts}

We prepared leaf extracts from five forest tree species in the laboratory to be used to water seeds and root cuttings of $S$. elaeagnifolium.

During the autumn of 2016, dry, recently fallen leaves and needles were collected from the ground of the dominant forests of the wider area of Thessaloniki. The leaves were selected from five forest tree species: Quercus pubescens Willd., Pinus brutia Ten., Quercus coccifera L., Pinus halepensis Miller, and Cupressus sempervirens $\mathrm{L}$. The collected leaves were put into plastic bags and transferred to the laboratory, where they were air-dried, cleaned of debris by hand and cut into small fragments. For each tree species, $100 \mathrm{~g}$ of leaves were put in a conical flask and mixed $(1: 10 \mathrm{w} / \mathrm{v})$ with distilled water (Scavo et al. 2020). The flasks sealed with a stopper and soaked for $24 \mathrm{~h}$ at room temperature until stirring (Morgan \& Overholt 2005, Fernandez et al. 2006, Bulut \& Demir 2007, Alrababah et al. 2009). Stirring was performed for 12 hours with 140 revolutions per minute, in four periods, each lasting 2, 4, 4 and 2 hours, respectively. Then, the leaf extracts were transferred into a $1000 \mathrm{ml}$ volumetric flask by filtration through filter paper (Whatman no. 2 - Bulut \& Demir 2007, Scavo et al. 2020). The final leaf extract of each species had a concentration of $20 \mathrm{~g} \mathrm{~L}^{-1}$ of distilled water. The leaf extracts were stored in a fridge at $1-3{ }^{\circ} \mathrm{C}$ temperature until the beginning of the experiment.

\section{Seed germination and root regenerative ability of the cuttings}

\section{First experiment}

In order to check if the leaf extracts of the forest tree species affect $S$. elaeagnifolium germination, seed germination trials were conducted. S. elaeagnifolium seeds were placed on two filter paper discs in each $9-\mathrm{cm}$ diameter Petri dish, and then covered with another filter paper disc. We defined six treatments (leaf extracts from five species plus a control) with three replicates of 100 seeds (ISTA 2020); the 100 seeds were distributed in four Petri dishes with twenty-five seeds in each dish and incubated in a growth chamber. Although an earlier study (Stanton et al. 2012) concluded that the highest germination (38\%) of S. elaeagnifolium was achieved at alternating temperature $25 / 15{ }^{\circ} \mathrm{C}$, in the current experiment we chose to study the effect at a constant temperature of $25 \pm 1{ }^{\circ} \mathrm{C}$ and a photoperiod of 12 hours. Seeds in each treatment were watered as needed to pro- vide seeds with an adequate moisture level (Ganatsas et al. 2019), respectively with a leaf extract of each of the five tree species, while in the control treatment the seeds watered with distilled water. Every $2^{\text {nd }}$ day the seeds were checked for germination and fungus infection for a duration of 45 days. Every $3^{\text {rd }}$ day the filter papers were changed to avoid fungal infection. Seeds were considered to be germinated when the rootlet had double the size of the seed diameter. Seeds that had germinated but had been infected by fungi were recorded and removed to avoid further contamination. In addition, the filter papers were sprayed with fungicide at every change, before placing them in the Petri dishes.

\section{Second experiment}

To test whether the root regenerative ability of the $S$. elaeagnifolium is affected by the leaf extracts of the forest tree species, the root cuttings were transplanted into transparent plastic pots of a size of $10 \times 10 \mathrm{~cm}$, filled with a peat perlite mix in a ratio $1: 1$. Cuttings were inserted vertically into the growing medium. Four treatments were applied with three replications each and five cuttings in each replication. Two of the treatments were watered with leaf extracts of $Q$. pubescens and $P$. brutia, respectively. The other two treatments were the control, where cuttings were watered with distilled water and a rooting hormone treatment, where the cuttings were dipped in the rooting hormone indole-3-butyric acid (IBA) before their insertion into the growing medium. The cuttings were then watered with distilled water and covered with a plastic membrane in order to keep the humidity high. The pots were put in a growth chamber with a controlled temperature of $25 \pm 1$ ${ }^{\circ} \mathrm{C}$ and $12 \mathrm{~h}$ photoperiod. Cuttings were checked for water needs and fungal infection. Root regenerative ability was evaluated after two weeks and measured as the number of root cuttings that produced a stem (Stanton et al. 2011).

\section{Statistical analysis}

Statistical analysis was performed by the SPSS $^{\oplus}$ software v. 23.0 (SPSS Inc., Chicago, IL, USA). The percentage values of seed germination and root regenerative ability, were arcsine-transformed to match the normality and homogeneity assumptions (Ganatsas et al. 2019). One-way ANOVA was used to test significant differences between the treatments. LSD and WallerDuncan tests were performed to compare the mean values of: (i) S. eleagnifolium density differentiation in the two forest ecosystems; (ii) seed germination and root regenerative ability of the cuttings among the treatments. Also, a t-test was used to detect differences in morphological characteristics of the fruits between the two sampled populations. All statistical analyses were conducted using the critical significance level $\alpha=0.05$.

\section{Results}

\section{Invasion of S. elaeagnifolium in forest ecosystems}

Field data analysis shows that S. elaeagnifolium is capable of establishing along the forest edges, but not in a typical forest environment (Fig. 1). In both forest ecosystems, the density of S. elaeagnifolium decreased with distance inside the forest relative to the forest edge. The highest species density (over 80,000 individuals ha $^{-1}$ ) appears at the limit of $Q$. coccifera forest (zero point), while the invasion is limited to $10 \mathrm{~m}$ from the forest edge, where $S$. elaeagnifolium density reaches 16,304 individuals ha'. In P. brutia ecosystem there is a further extension of the species inside the forest, up to a distance of $30 \mathrm{~m}$ from the forest edge $(12,245$ individuals ha' $)$ while it is absent at $50 \mathrm{~m}$ from the edge. In P. brutia ecosystem the density of $S$. elaeagnifolium was significantly higher at all distances than that of Q. coccifera forest ecosystem, except for the zero point where the density was significantly higher in the Q. coccifera ecosystem.

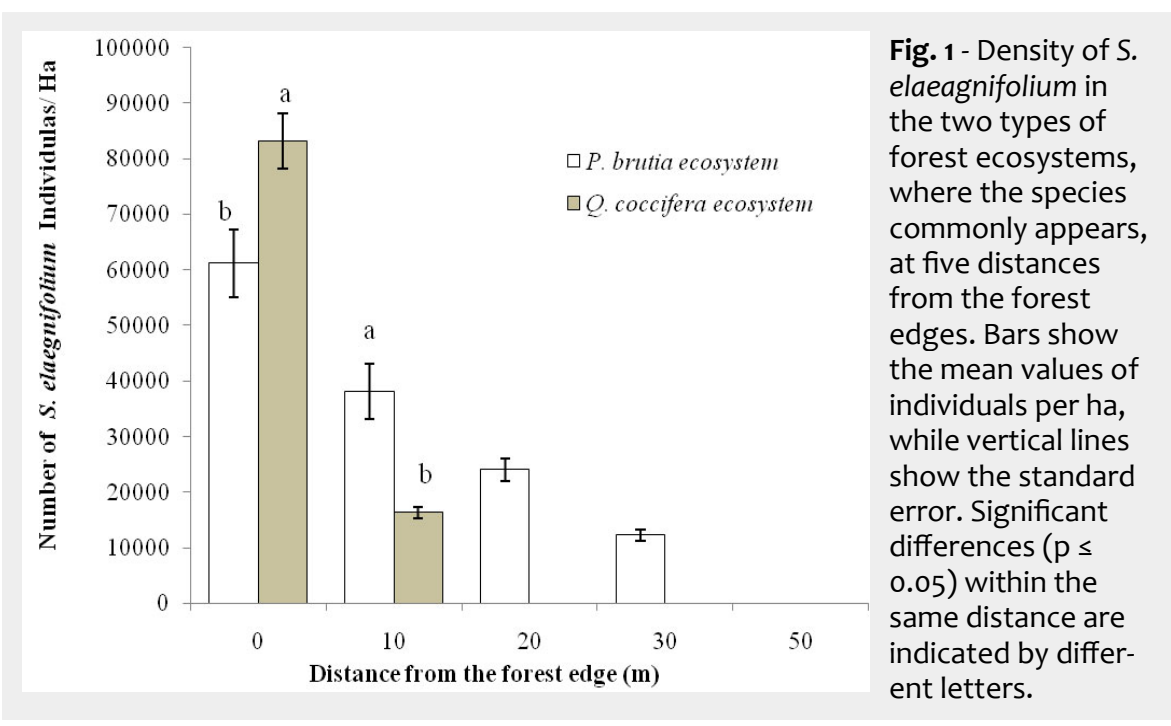


Tab. 1 - Morphological characteristics of Solanum elaeagnifolium fruits. Values are means \pm standard errors $(N=50$ per population). Significant $(p \leq 0.05)$ difference within columns are indicated by different letters.

\begin{tabular}{lcc}
\hline Population region & Thessaloniki & Dion \\
\hline Fruit diameter $(\mathrm{cm})$ & $1.431 \pm 0.028^{\mathrm{a}}$ & $1.340 \pm 0.026^{\mathrm{b}}$ \\
\hline Fruit vertical length $(\mathrm{cm})$ & $1.252 \pm 0.022^{\mathrm{a}}$ & $1.222 \pm 0.025^{\mathrm{a}}$ \\
\hline Stem imprint diameter $(\mathrm{cm})$ & $0.490 \pm 0.026^{\mathrm{a}}$ & $0.456 \pm 0.007^{\mathrm{a}}$ \\
\hline Number of seeds per fruit & $95.13 \pm 5.432^{\mathrm{a}}$ & $54.60 \pm 3.428^{\mathrm{b}}$ \\
\hline
\end{tabular}

\section{Fruit morphological characteristics}

Fruit diameter, fruit vertical length, stem imprint diameter and number of seeds per fruit for the two studied populations are shown in Tab. 1. Fruit diameter and number of seeds statistically differ between the two populations. Fruits of the Thessalonik area had significantly larger diameter compared to those from the Dion area (1.43 vs. $1.34 \mathrm{~cm}$, respectively), and almost twicefold number of seeds per fruit (95.1 and 54.6 , respectively).

\section{Effect of leaf extracts on seed germination}

Final seed germination percentages and cumulative germination are shown in Fig. 2. Seeds watered with distilled water (control) and P. halepensis leaf extract presented higher germination compared to the other treatments. All the other tree leaf extracts significantly inhibited the germination of S. elaeagnifolium; the leaf extract of Q. pubescens had the highest inhibitory activity, resulting in a very low seed germination (4\%). Treatments also affected the speed of germination; seed germination started at the $8^{\text {th }}$ day for the control treatment, while the use of leaf extracts retarded the germination. The leaf extracts of $P$. brutia had the higher effect, being the germination started 18 days later

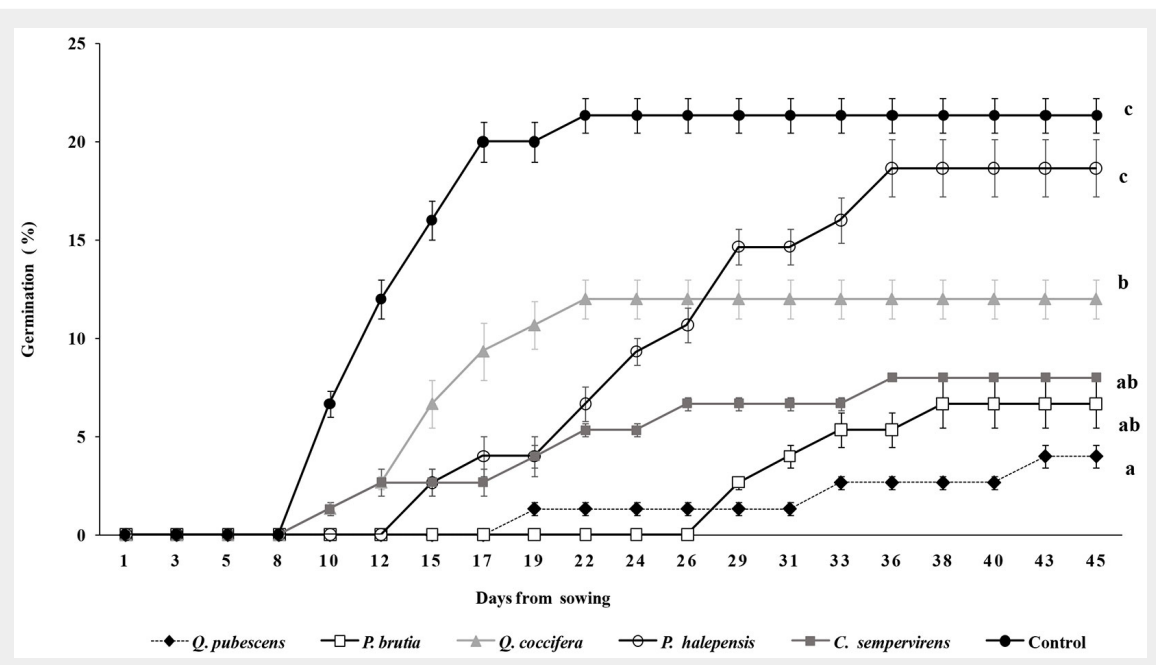

Fig. 2 - Cumulative seed germination percentages of S. elaeagnifolium as affected by the watering with the five tree leaf extracts. Vertical lines represent the standard error. Different low case letters indicate significant differences at $p \leq 0.05$.

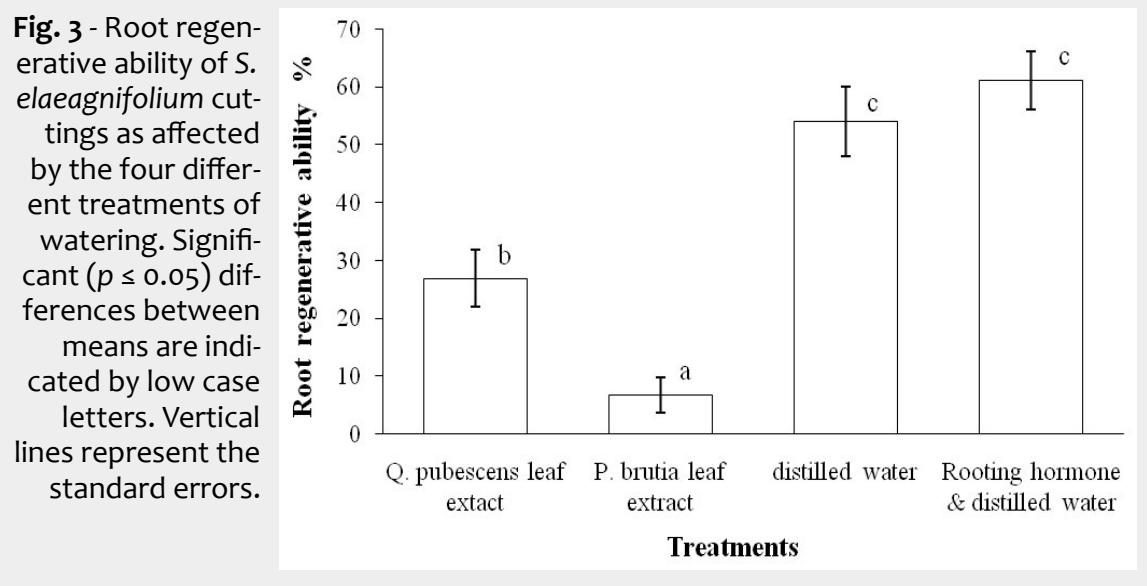

compared to the control.

\section{Effect of leaf extracts on root}

regenerative ability

Percentages of root regenerative ability for each treatment applied are shown in Fig. 3. The watering with P. brutia leaf extract had significantly the highest inhibitory activity on S. elaeagnifolium root regenerative ability, resulting in a very low value (6.67\%), followed by the watering with $Q$. pubescens leaf extract. The percentage values of root regenerative ability in the other treatments applied were moderate, and did not statistically differ.

\section{Discussion}

Natural forests are generally considered less prone to biological invasions than other ecosystems, particularly when canopy cover is high. On the contrary, forest edges (roads, clearcuts, burned forests) are the first landscape elements invaded by alien plant species in forest ecosystems (Pauchard \& Alaback 2006). This idea was confirmed by our results; based on field data, S. elaeagnifolium was mostly found along the forest edges, in a more human disturbed environment with no or loose tree canopy. Few individuals were found inside the forest close to the edge, but this zone, from an ecological point of view, can be characterized as edge environment. In fact, forest edge is the transition zone (ecotone) from an area of forest to open spaces. This open forest boundary differs from the forest interior in microclimatic conditions (i.e., greater wind speed and air temperature, decreased humidity, altered light conditions, soil moisture, and levels of photosynthetically active radiation), that favors the growth of opportunistic species (Chen et al. 1995, Davies-Colley et al. 2000). Young \& Mitchell (1994) reported that the influence of open forest boundary on moisture and temperature extended up to $50 \mathrm{~m}$ into the forest from the forest edge. Similarly, in our study, in P. brutia ecosystem a distance of $50 \mathrm{~m}$ from the forest edge seems to be adequate to form a closed forest environment that prevents S. elaeagnifolium recruitment and survival. This distance is much lower in the case of Q. coccifera ecosystem, probably due to the lower tree height that may affect the width of forest edge influence.

The absence of S. elaeagnifolium from forest ecosystems can be attributed to a combination of factors. Indeed, this exclusion may be party attributed to the forest canopy closure, in combination with herb vegetation and thick litter layer that reduce the light availability, and increase water competition, especially during the summer, and make the habitat less favorable for the reproduction and expansion of $S$. elaeagnifolium. According to the study of Boyd \& Murray (1982a), 80\% level of shade under the canopies of cotton and grain sorghum would be sufficient to inhibit S. elaeagnifolium development if it was present prior 
to the onset of growth. Khaniya \& Shrestha (2020), studying 14 invasive tropical plants reported similar results, finding that the increased canopy cover and the closure of forest gaps can prevent plant invasions and suppress the growth of established invasive plants in Shorea robusta forests of Nepal.

Beyond the effect of shading, forest canopy cover may also inhibit the species' reproductive activity in other ways. For example, the emergence of $S$. elaeagnifolium seedlings has been observed in the field from February to April (Uludag et al. 2016) after high rainfall. Rainfall probably could be a crucial factor in breaking high dormancy levels of the S. elaeagnifolium seeds, by washing the mucus coat off the seeds. Under a dense forest canopy, rain drops do not fall with high intensity and the stem flow conveys a high amount of water intercepted by the forests canopy and bark (Van Dijk \& Bruijnzeel 2001, Levia \& Herwitz 2005, Limin et al. 2015). Moreover, the forest terrain, which is usually covered by low vegetation and a thick litter layer, prevents water from entering soil with high intensity (Owens et al. 2006). All these could contribute to the preservation of the sticky coat film on the seeds, which in turn may result in high seed dormancy levels.

Another possible explanation for the inhibition of S. elaeagnifolium inside forest ecosystems could be related to the studied forest ecosystems, which have not recently undergone strong anthropogenic disturbances (e.g., soil tillage, recent reforestation works, road construction). Ganatsas et al. (2012) recorded S. elaeagnifolium populations in northern Greece in forest habitats that had been recently disturbed, such as the newly established reforestations. Similarly, Langmaier \& Lapin (2020) claim that during plantation establishment and after anthropogenic disturbances due to silvicultural treatments (e.g., soil preparation), forest ecosystems may be heavily impacted by alien plant invasions due to the light and nutrient availability that boosts competition for limited sources. Thus, $S$. elaeagnifolium appears to have a vigorous spreading ability on bare disturbed areas under full sunlight reception (Boyd \& Murray 1982 b), low competitiveness and increased nutrients uptake at an individual level (Vila \& Weiner 2004). On the contrary in a forest ecosystem, the high tree density and the dense tree root systems, which are commonly very competitive for nutrients and water, could create adverse conditions for the establishment of S. elaeagnifolium. Considering the above, in managed forests in the Mediterranean basin, the selection loggings or shelterwood systems applied in close-to-nature silviculture should be preferred (Langmaier \& Lapin 2020).

The results of our study indicated that $S$. elaeagnifolium spreading ability into forest ecosystems may be also hampered by the allelopathic effect of forest trees leaf extracts. Similar allelopathic effect has been reported for some other invasive plants (Morgan \& Overholt 2005, Fernandez et al. 2006, Alrababah et al. 2009, Zhang et al. 2012). According to the results of the first experiment, the leaf extracts of $Q$. pubescens, P. brutia, C. sempervirens, and Q. coccifera significantly inhibited the germination of S. elaeagnifolium compared to the control, while the highest inhibitory activity was presented by Q. pubescens. Also from the results of our second experiment, it is clear that the leaf extracts from P. brutia and Q. pubescens significantly inhibited the root regenerative ability of S. elaeagnifolium. Zhang et al. (2012), found that the essential oils from certain eucalyptus species in Australia had an inhibitory effect on S. elaeagnifolium germination, root growth and shoot growth. From an ecological perspective, allelopathy plays a role in biological invasion: some plants use chemical compounds as weapons against native plants (Scognamiglio et al. 2013). However, though our experiments showed a significant effect of forest trees' leaf extracts on S. elaeagnifolium reproductive ability, we should cautiously consider that we tested leaf extracts in laboratory conditions, while under the forest conditions the natural processes may greatly differ. The function of plant allelochemicals in the rhizosphere not always affect the target plant, since a variety of other biotic and abiotic factors play a key role in determining their adsorption and transport into the forest soil.

In summary, despite the inability of $S$. elaeagnifolium to spread in a close forest ecosystem, it remains a major threat to natural ecosystems. In case of a forest fire, S. elaeagnifolium could colonize the burnt bare land (Roche 1991) as an invading species and could dominate the area competing the local pioneer tree species. Under the current and future climatic scenarios, plant species that are tolerant to abiotic stress (heat, drought), such as $S$. elaeagnifolium, are expected to have an advantage over species that are more sensitive to these factors (Christodoulakis et al. 2009, Uludag et al. 2016, Adhikari et al. 2019). In the context of climate change, especially in hot and dry Mediterranean areas, and the expected increase in disturbances in forest canopies, studies on demographic traits of this invasive alien species are important for the survival of forest ecosystems in the future.

This study is part of an ongoing research aimed to devise effective management practices to prevent future invasions of this severe invasive alien plant.

\section{Conflicts of interest}

The authors declare no conflicts of interest.

\section{Acknowledgments}

The authors acknowledged three anonymous reviewers for their valuable comments and recommendations to increase the reader's interest in the paper. Special thanks to Mrs. Sevasti Tsaggari-Preka for the revision of English language.

\section{References}

Adhikari P, Jeon JY, Kim HW, Shin MS, Adhikari P, Seo C (2019). Potential impact of climate change on plant invasion in the Republic of Korea. Journal of Ecology and Environment 43 (1): 36. - doi: 10.1186/s41610-019-0134-3

Alrababah MA, Tadros MJ, Samarah NH, Ghosheh $\mathrm{H}$ (2009). Allelopathic effects of Pinus halepensis and Quercus coccifera on the germination of Mediterranean crop seeds. New Forests 38: 261-272. - doi: 10.1007/s11056-009-9145-8

Baye Y, Ameur A, Bouhaches M, Taleb A (2007). Strategy for the chemical control of Solanum elaeagnifolium Cav. in Morocco. EPPO Bulletin 37: 145-152. - doi: 10.1111/j.1365-2338.2007.01092. $\mathrm{x}$

Boyd JW, Murray DS (1982a). Growth and development of Silverleaf nightshade (Solanum elaeagnifolium). Weed Science 30: 238-243. - doi: 10.1017/So043174500040455

Boyd JW, Murray DS (1982b). Effects of shade on Silverleaf nightshade (Solanum elaeagnifolium). Weed Science 30: 264-269. - doi: 10.1017/So0431 74500040509

Brunel S, Schrader G, Brundu G, Fried G (2010). Emerging invasive alien plants for the Mediterranean Basin. OEPP/EPPO Bulletin 40: 219-238. doi: 10.1111/j.1365-2338.2010.02378.x

Brunel S (2011). Pest risk analysis for Solanum elaeagnifolium and international management measures proposed. EPPO Bulletin 41: 232-42. doi: 10.1111/j.1365-2338.2011.02457.x

Bulut Y, Demir M (2007). The allelopathic effects of Scots Pine (Pinus sylvestris L.) leaf extracts on turf grass seed germination and seedling growth. Asian Journal of Chemistry 19 (4): 31693177. [online] URL: http://www.researchgate. net/publication/288446992

Cambardella CA, Elliott ET (1992). Particulate soil organic-matter changes across a grassland cultivation aequence. Soil Science Society of America Journal 56: 777-783. - doi: 10.2136/sssaj 1992.03615995005600030017x

Chen J, Franklin JF, Spies TA (1995). Growingseason microclimatic gradients from clearcut edges into old-growth Douglas-fir forests. Ecological Applications 5: 74-86. - doi: 10.2307/194 2053

Choudhary M, Bordovsky DG (2006). Timing of glyphosate application on control of Silverleaf nightshade and glyphosate-resistant cotton yield. Weed Technololgy 20: 198-203. - doi: 10.1614/WT-04-132R2.1

Christodoulakis NS, Lampri PN, Fasseas C (2009). Structural and cytochemical investigation of the leaf of silverleaf nightshade (Solanum elaeagnifolium), a drought-resistant alien weed of the Greek flora. Australian Journal of Botany 57: 432-438. - doi: 10.1071/BT08210

Cummings J, Parker I, Gilbert G (2012). Allelopathy: a tool for weed management in forest restoration. Plant Ecology 213 (12): 1975-1989. - doi: 10.1007/s11258-012-0154-x

Davies-Colley RJ, Payne GW, Van Elswijk M (2000). Microclimate gradients across a forest edge. New Zealand Journal of Ecology 24: 111121. [online] URL: http://www.jstor.org/stable/ 24054666 
EPPO (2007). Datasheets on quarantine pests. Solanum elaeagnifolium. EPPO Bulletin 37: 236 245. - doi: 10.1111/j.1365-2338.2007.01112.x

Fernandez C, Lelong B, Vila B, Mevy JP, Robles C, Greff S, Dupouyet S, Bousquet-Melou A (2006). Potential allelopathic effect of Pinus halepensis in the secondary succession: an experimental approach. Chemoecology 16: 97-105. - doi: 10.10 07/s00049-006-0334-z

Ganatsas P, Tsitsoni T, Tsakaldimi M, Zagas T (2012). Reforestation of degraded Kermes oak shrublands with planted pines: effects on vegetation cover, species diversity and community structure. New Forests 43: 1-11. - doi: 10.1007/s11 056-011-9262-z

Ganatsas P, Tsakaldimi M, Damianidis C, Stefanaki A, Kalapothareas T, Karydopoulos T, Papapavlou K (2019). Regeneration ecology of the rare plant species Verbascum dingleri: implications for species conservation. Sustainability 11 3305: 1-13. - doi: 10.3390/su11123305

Gitsopoulos TK, Damalas CA, Georgoulas I (2017). Chemical options for the control of Silverleaf nightshade (Solanum elaeagnifolium). Planta Daninha 35: e017162035. - doi: 10.1590/so 100-83582017350100064

Hashim A, Mousawi A, Al-Naib F (1975). Allelopathic effects of Eucalyptus microtheca $F$. Muell. Kuwait Journal of Science 2: 59-66.

Honnay O, Verheyen K, Hermy M (2002). Permeability of ancient forest edges for weedy plant species invasion. Forest Ecology and Management 161: 109-122. - doi: 10.1016/S0378-1127(01) 00490-X

ISTA (2020). International rules for seed testing. The International Seed Testing Association ISTA, Bassersdorf, Switzerland. pp. i-19-8.

Khaniya L, Shrestha BB (2020). Forest regrowth reduces richness and abundance of invasive alien plant species in community managed Shorea robusta forests of central Nepal. Journal of Ecology and Environment 44: 12. - doi: 10.118 6/s41610-020-00158-7

Krigas N, Votsi NE, Katsoulis G, Tsiafouli M (2016). Climate creates limitations, soil disturbance favours and roads pave the way for the invasion of Solanum elaeagnifolium CAV. (Solanaceae), even in protected areas. In: Proceedings of the " 8 th Congress of the Hellenic Ecological Society: 150+ Years of Ecology-Structures, Dynamics and Survival Strategies". Thessaloniki (Greece) 20-23 Oct 2016. Hellenic Ecological So ciety, Greece, pp. 127.

Langmaier M, Lapin K (2020). A systematic review of the impact of invasive alien plants on forest regeneration in European temperate forests. Frontiers in Plant Science 11: 1974. - doi: $10.3389 / f p l s .2020 .524969$

Levia DF, Herwitz SR (2005). Interspecific variation of bark water storage capacity of three deciduous tree species in relation to stemflow yield and solute flux to forest soils. Catena 64 : 117-137. - doi: 10.1016/j.catena.2005.08.001

Lill RE, Waid JS (1975). Volatile phytotoxic substances formed by litter of Pinus radiata. New Zealand Journal of Forestry Science 5: 165-170. [online] URL: http://www.scionresearch.com/ _data/assets/pdf_file/0014/31019/NZJFS51975L
ILL165_170.pdf

Limin SG, Oue H, Sato Y, Budiasa IW, Setiawan BI (2015). Partitioning rainfall into throughfall, stemflow, and interception loss in clove (Syzygium aromaticum) plantation in Upstream Saba River Basin, Bali. Procedia Environmental Sciences 28: 280-285. - doi: 10.1016/j.proenv.2015. 07.036

Mekki M (2006). Potential threat of Solanum elaeagnifolium Cav. to the Tunisian fields. In: Proceedings of the "International Workshop: Invasive Plants in Mediterranean Type Regions of the World". Mèze (France) 25-27 May 2005. Council of Europe publishing, Strasbourg, France, pp. 165-170. - [online] URL: http://cite seerx.ist.psu.edu/viewdoc/download?doi=10.1.1. 115.6608\&rep=rep1\&type=pdf\#page $=165$

Mekki M (2007). Biology, distribution and impacts of Silverleaf nightshade (Solanum elaeagnifolium (av.). EPPO Bulletin 37: 114-118. - doi: 10.1111/j.1365-2338.2007.01094.x

Morgan EC, Overholt WA (2005). Potential allelopathic effects of Brazilian pepper (Schinus terebinthifolius Raddi, Anacardiaceae) aqueous extract on germination and growth of selected Florida native plants. The Journal of the Torrey Botanical Society 132: 11-15. - doi: 10.3159/10955674(2005)132[11:PAEOBP]2.0.CO;2

Owens MK, Lyons RK, Alejandro CL (2006). Rainfall partitioning within semiarid juniper communities: effects of event size and canopy cover. Hydrological Processes 20: 3179-3189. - doi: 10.1002/hyp.6326

Pauchard A, Alaback PB (2006). Edge type defines alien plant species invasions along Pinus contorta burned, highway and clearcut forest edges. Forest Ecology and Management 223: 327-335. - doi: 10.1016/j.foreco.2005.11.020

Phillips ML, McNellis BE, Allen MF, Allen EB (2019). Differences in root phenology and water depletion by an invasive grass explains persistence in a Mediterranean ecosystem. American Journal of Botany 106 (9): 1210-1218. - doi: 10.1002/ajb2.1344

Rice EL (2012). Allelopathy ( $2^{\text {nd }}$ edn). Academic Press, New York, USA, pp. 368. [online] URL: http://books.google.com/books?id=uqcH7AOX MCUC

Roche C (1991). Silverleaf nightshade. Publication no. 365, Pacific Northwest Extension, Washington State University, Pullman, WA, USA, pp. 5-6.

Sayari N, Brundu G, Mekki M (2016). Mapping and monitoring an invasive alien plant in Tunisia: Silverleaf nightshade (Solanum elaeagnifolium) a noxious weed of agricultural areas. Tunisian Journal of Plant Protection 11: 219-227. [online] URL: http://www.tjpp.tn/SiteWeb/Prev iouslssues/TJPP11-2/4Sayari2.pdf

Scavo A, Mauromicale G (2020). Integrated weed management in herbaceous field crops. Agronomy 10 (4): 466. - doi: 10.3390/agronomy 10040466

Scavo A, Pandino G, Restuccia A, Mauromicale G (2020). Leaf extracts of cultivated cardoon as potential bioherbicide. Scientia Horticulturae 261 (2): 109024. - doi: 10.1016/j.scienta.2019.109 024
Scognamiglio M, D’Abrosca B, Esposito A, Pacifico S, Monaco P, Fiorentino A (2013). Plant growth inhibitors: allelopathic role or phytotoxic effects? Focus on Mediterranean biomes. Phytochememistry Reviews 12: 803-830. - doi: 10.1007/s11101-013-9281-9

Sforza R, Jones WA (2007). Potential for classical biocontrol of silverleaf nightshade in the Mediterranean Basin. EPPO Bulletin 37: 156-162. - doi: 10.1111/j.1365-2338.2007.01109.x

Singh D, Kohli RK (1992). Impact of Eucalyptus tereticornis Sm. shelterbelts on crops. Agroforestry Systems 20: 253-266. - doi: 10.1007/BFooo 53143

Stanton RA, Heap JW, Carter RJ, Wu H (2007). Solanum elaeagnifolium. OEPP/EPPO Bulletin 37: 236-245. - doi: 10.1111/j.1365-2338.2007.0111 2.x

Stanton R, Wu H, Lemerle D (2011). Root regenerative ability of Silverleaf nightshade (Solanum elaeagnifolium (av.) in the glasshouse. Plant Protection Quarterly 26: 54-56.

Stanton R, Wu H, Lemerle D (2012). Factors af fecting Silverleaf nightshade (Solanum elaeagnifolium) germination. Weed Science 60: 42-47. - doi: 10.1614/WS-D-11-00105.1

Sturm DJ, Peteinatos G, Gerhards R (2018). Contribution of allelopathic effects to the overall weed suppression by different cover crops. Weed Research 58 (5): 331-337. - doi: 10.1111/ wre.12316

Thapa S, Chitale V, Rijal SJ, Bisht N, Shrestha BB (2018). Understanding the dynamics in distribution of invasive alien plant species under predicted climate change in Western Himalaya. PLoS One 13(4): e0195752. - doi: 10.1371/journal. pone. 0195752

Tolliver KS, Colley DM, Young DR (1995). Inhibitory effects of Myrica cerifera on Pinus taeda. The American Midland Naturalist Journal 133: 256-263. - doi: 10.2307/2426389

Uludag A, Gbehounou G, Kashefi J (2016). Review of the current situation for Solanum elaeagnifolium in the Mediterranean Basin. EPPO Bulletin 46: 139-147. - doi: 10.1111/epp.12266

Van Dijk AIJ, Bruijnzeel LA (2001). Modelling rainfall interception by vegetation of variable density using an adapted analytical model. Part 1. Model description. Journal of Hydrology 247: 230-238. - doi: 10.1016/So022-1694(01)00392-4

Vila M, Weiner J (2004). Are invasive plant species better competitors than native plant species? - evidence from pair-wise experiments. Oikos 105: 229-238. - doi: 10.1111/j.0030-1299.20 04.12682.X

Young A, Mitchell N (1994). Microclimate and vegetation edge effects in a fragmented podocarp broadleaf forest in New Zealand. Biological Conservation 67: 63-72. - doi: 10.1016/00063207(94)90010-8

Zhang J, An M, Wu H, Liu DL, Stanton R (2012). Chemical composition of essential oils of four Eucalyptus species and their phytotoxicity on Silverleaf nightshade (Solanum elaeagnifolium (av.) in Australia. Plant Growth Regulation 68: 231-237. - doi: 10.1007/s10725-012-9711-5 